2. Авдеева Ж.И. К иммунообразующей активности лимфоцитов крови человека под влиянием гаммаинтерферона и рекомбинантного альфа-интерферона. // Вестн. дермат. и венерол. 2017. - №4.- С. -16.

3. Авдеева Ж.И. К иммуномодулирующему действию препаратов интерферона. //Вестн. дермат. и венер. 2019. -№ 8. - С.23-28.

4. Азнабаев М.Т., Латыпова Э.А., Мальханов В.Б. Применение препарата циклоферона при комплексном лечении хламидийного конъюнктивита.- // Вестник офтальмологии №1-2021.- С.38-39.

5. Акберова С.И.- Актипол в лечении стромального герпетического кератита.- // Вестник офтальмологии №22018.- С.17-19.

6. Акберова С.И.- ПАБК и перспективы ее применения в офтальмологии. // Вестник офтальмологии №3- 2019.C.53-56.

7. Ариненко Р.Ю. Система интерферона: первая линия защиты организма. //Terra med. 1997. - №4. - С. 11-14.

\title{
Павленко Н.В. \\ Контроль качества лекарственных препаратов для детей в условиях аптеки
}

Северо-Осетинский государственный университет имени К.Л. Хетагурова

(Россия, Владикавказ)

doi: 10.18411/trnio-01-2022-212

\section{Аннотация}

На современном этапе выделяют особую группу лекарственных средств, специально предназначенных для использования в детской практике. К препаратам, применяемым у детей, предъявляются особые требования. Прежде всего, это обусловлено анатомо-физиологическими особенностями детского организма, которые в значительной степени отличаются от организма взрослого. Основные требования, выдвигаемые к лекарственным препаратам для детей, - это их эффективность и безопасность. Этим вопросам посвящают специальные доклинические исследования, на основе которых принимаются решения относительно возможности использования определенного лекарственного средства у детей различных возрастных периодов.

Ключевые слова: качество, лекарственные препараты, дети.

\section{Abstract}

At the present stage, there is a special group of medicines specially designed for use in children's practice. There are special requirements for drugs used in children. First of all, this is due to the anatomical and physiological characteristics of the child's body, which are significantly different from the adult's body. The main requirements for medicines for children are their effectiveness and safety. Special preclinical studies are devoted to these issues, on the basis of which decisions are made regarding the possibility of using a certain drug in children of different age periods.

Keywords: quality, medicines, children.

Разработка педиатрических препаратов сложна, поскольку необходимо понимать физиологические изменения развития, происходящие в детстве, и их влияние на абсорбцию лекарств. Педиатрические корректировки дозы обычно основываются на достижении фармакокинетических или фармакодинамических профилей, эквивалентных профилям, достигнутым во взрослой популяции. Однако различия в том, как дети обращаются с продуктами для взрослых, или в использовании специальных педиатрических составов, могут привести к неожиданным фармакокинетическим профилям лекарств с измененной клинической эффективностью. Специалисты здравоохранения, участвующие в назначении, введении или отпуске лекарств детям, должны понимать различия в лекарственных формах, чтобы они давали соответствующие рекомендации для достижения терапевтических результатов. Эта проблема не ограничивается пероральными лекарствами, но применима для всех способов введения, встречающихся в педиатрической терапии. 
Разработка соответствующих возрасту лекарств для детей требует не только понимания их предпочтений в отношении различных составов, вкусов и текстур продуктов, но также понимания физических и биохимических различий между детьми и взрослыми. Наиболее очевидное различие между лекарственной терапией для взрослых и детей заключается в сложности корректировки дозы и алгоритмов, используемых для расчета дозировок, относящихся к подгруппам в пределах всей педиатрической популяции. С точки зрения лекарственной терапии большое внимание уделяется идиоме, что «дети - не просто маленькие взрослые». Действительно, рост и развитие - это два основных аспекта детей, которые не всегда очевидны у взрослых. Тема человеческого роста и развития обширна и содержит множество подробных специализированных справочных работ.

Есть несколько обзоров, в которых подробно описаны варианты составов и их пригодность для детей в возрасте от 4 до 8 лет. Также существует нормативное руководство по предпочтению рецептур с возрастом в педиатрической популяции 9-11 лет. Тем не менее, по-прежнему существует потребность в информации, основанной на доказательствах, для руководства разработкой рецептур, подходящих и приемлемых для детей и молодежи.

В связи с широким возрастным диапазоном педиатрической популяции маловероятно, что одна рецептура будет подходящей для этого диапазона, что требует нескольких вариантов продукта. При разработке идеального состава для педиатрии необходимо учитывать следующие факторы:

- оказывает минимальное влияние на образ жизни ребенка, проявляясь в наименьшей частоте дозирования и приятном на вкус продукте;

- обеспечение индивидуального дозирования или диапазонов доз, подходящих для эффективной терапии;

- достаточная биодоступность;

- н нетоксичные вспомогательные вещества в составе;

- удобное и надежное администрирование;

- надежный производственный процесс при минимальных затратах.

Широко распространено использование нелицензированных и нерекомендуемых лекарств для лечения детей, что сопряжено с риском, поскольку эти продукты не были должным образом изучены в педиатрической практике. Медицинским работникам и родителям или опекунам часто требуется манипулировать лекарством для взрослых, чтобы получить подходящую дозу для ребенка, например, разделив таблетку для получения меньшей дозы или, в более сложных случаях, приготовив суспензию из измельченной таблетки. Такие манипуляции увеличивают вариабельность продукта из-за неточных измерений, проблем со стабильностью или ошибок в инструкциях по манипуляциям 13. В настоящее время существуют нормативные и финансовые стимулы для разработки соответствующих возрасту лекарств для новых лекарств, однако существует значительное количество существующих лекарств, для которых необходимы соответствующие возрасту составы. Для таких лекарств есть списки приоритетов.Фармацевтический состав может влиять на эффективность лекарственного средства, особенно в отношении продуктов, приготовленных для немедленного приема, которые вводят детям. В одном описанном клиническом исследовании описана значительная недостаточная дозировка клобазама у 3летнего ребенка с эпилепсией. В этом случае препарат для немедленного приема, хотя и был приготовлен в правильной номинальной концентрации, не соответствовал назначению, поскольку активное лекарственное средство не было суспендировано однородно. Правильный введенный объем не содержал правильной дозы, что привело к субтерапевтическому лечению.

Вывод: Препараты, разрешенные для приема детям, не должны содержать эксипиентов или действующего вещества, которые влияют на рост и развитие тканей, снижают иммунитет, являются токсичными. Например, тетрациклины нарушают зубную эмаль у детей, влияют на рост костей; стрептомицин и гентамицин могут вызывать глухоту. 
Детям в возрасте до года запрещено принимать лекарства, которые содержат спирт. Таким образом, мы можем прийти к выводу, что особенности детского организма и изменение этиологической структуры заболеваний в современных условиях обязывают искать новые подходы к наиболее адекватному выбору терапии. Конечный результат лечения зависит от правильного выбора препаратов и их форм.

$$
* * *
$$

1. Ажгихин И.С. Технология лекарств. Москва: «Медицина» - 1980, с.440

2. Баранов А.А. Здоровье детей России: научные и организационные приоритеты //Педиатрия. 2013, N.3. 4-7

3. Государственная фармакопея, XIV издание - Москва: 2015г., 7020с. Обновлёна 30 ноября 2018.

4. Гельперина С. Э. Системы доставки лекарственных веществ на основе полимерных наночастиц / С. Э. Гельперина, В. И. Швец // Биотехнология. -2014.-№3.-С. 8-23.

\section{Павленко Н.В.}

Создание асептических условий в аптеке для изготовления лекарственных препаратов для детей

Северо-Осетинский государственный университет имени К.Л. Хетагурова (Россия, Владикавказ)

doi: 10.18411/trnio-01-2022-213

\section{Аннотация}

Асептика - это комплекс организационных мероприятий, направленных на предотвращение попадания микроорганизмов в лекарственную форму. Соблюдение асептических условий обязательно при изготовлении всех стерильных растворов, в том числе подвергающихся в дальнейшем стерилизации. Простерилизованные лекарственные формы, но загрязненные микрофлорой могут вызывать различные побочные явления за счет погибших микроорганизмов и их токсинов. препараты.

Ключевые слова: ассептические условия, дети, изггтовление, лекарственнфе

\section{Abstract}

Asepsis is a set of organizational measures aimed at preventing the ingress of microorganisms into the dosage form. Compliance with aseptic conditions is mandatory in the manufacture of all sterile solutions, including those undergoing further sterilization. Sterilized dosage forms, but contaminated with microflora, can cause various side effects due to dead microorganisms and their toxinsof an adult, which is due to the characteristics of the child's body.

Keywords: asseptic conditions, children, food preparation, medicinal preparations.

Когда в 2012 году в Соединенных Штатах прокатилась вспышка грибкового менингита, затронувшая более 800 человек, Управление по санитарному надзору за качеством пищевых продуктов и медикаментов установило, что вспышка возникла в аптеке в Массачусетсе. Расследование выявило грубые ошибки в составных стерильных препаратах. Было особо отмечено, что сбои в применении асептических методов способствовали загрязнению.

Асептический метод относится к определенному набору практик, выполняемых в определенных клинических условиях для предотвращения распространения патогенов и создания стерильной среды. В аптеках обычно требуется выполнять полную асептическую технику - в отличие от стандартных чистых методов, применяемых во всех медицинских учреждениях.

Тем не менее, такие инциденты, как вспышка менингита в Соединенных Штатах, подчеркивают важность получения надлежащего обучения асептическим методам для всех, кто хочет стать фармацевтом. Есть четыре основных элемента техники асептики, которые 